\title{
The time for macroeconomics in municipal food policy
}

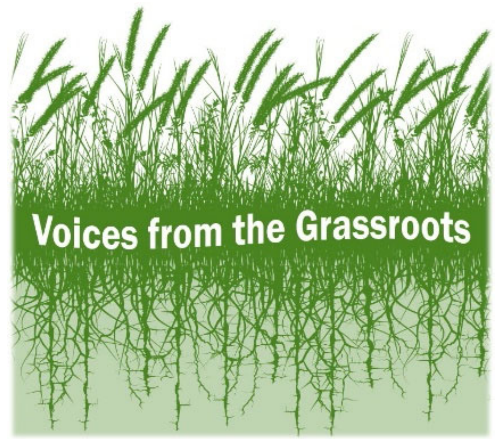

\author{
Shellye Suttles* \\ City of Indianapolis, Indiana
}

Submitted December 28, 2018/ Revised February 6, 2019 / Published online March 28, 2019

Citation: Suttles, S. (2019). The time for macroeconomics in municipal food policy.

Journal of A griculture, F ood Systems, and Community D evelopment, 8(4), 29-32.

https:/ / doi.org/ 10.5304/ jafscd.2019.084.023

Copyright (C) 2019 by the Author. Published by the Lyson Center for Civic Agriculture and Food Systems. Open access under CC-BY license.

$I_{\text {ta }}$ t's interesting - I've never felt like so much of an outsider as being an agricultural economist working on municipal food policy. And I'm a black woman in the United States. Prior to being the food policy and program coordinator for the City of Indianapolis, I was a research economist who studied local food systems, alternative energy, and climate change. Now, as a food policy practitioner, I have found that relevant aspects of classical macroeconomic theory often go ignored in municipal food policy, particularly the concept of economic change over time.

* Shellye Suttles is the food policy and program coordinator for the City of Indianapolis, Indiana. Her community engagement and research interests include socially disadvantaged farmers, social impacts of limited food access, and environmental effects of local food production. She also enjoys trying new restaurants in Indianapolis's International Marketplace. She can be reached at the O ffice of Public Health \& Safety, City of Indianapolis; 200 East Washington Street, Suite 2141; Indianapolis, Indiana 46204 USA; shellye.suttles@ indy.gov
In discussions with other food system practitioners, I am always prepared to explain the importance of incorporating economic theory into municipal food policy. I most often highlight the fact that economics is not capitalism. Rather, economics is a social science that studies production, distribution, and consumption of goods and services. Economics is further split up into two studies based on the unit of study: microeconomics and macroeconomics. Microeconomics studies individual economic decisions. For instance, microeconomists would study how an individual goes about finding a job while considering their education level, financial constraints, mobility constraints, and personal preferences. Meanwhile, macroeconomics studies the economy as a whole (American Economic Association, n.d.). Macroeconomists would be more interested in overall unemployment rates, as well as the social and political conditions that contribute to this rate. 
While most Americans are somewhat familiar with capitalism, which is one type of macroeconomic system, a variety of macroeconomic systems exist across the globe. Macroeconomic systems are defined by ownership, resource allocation, or political ideology, and include socialism, capitalism, mixed economies, etc. Capitalism is simply one type of macroeconomic system in which capital goods are owned by private individuals with the goal of capital accumulation. Thus economics is a tool to understand the dynamics of all economic systems, including capitalism.

Economics has always concerned itself with food and agriculture. Hesiod, the famous $G$ reek poet and the world's first "economist," often wrote about farming techniques, food production, and economic thought sometime between 750 and 650 BC. Adam Smith's famous W ealth of N ations (1776) was written solely to counter French economic thought on how best to value agricultural land. Economics should not be feared or excluded from the conversation on economic change in the food system. Instead, it ought to be considered a tool to understand the intersection between people, food, politics, agriculture, public health, and the environment.

Food policy practitioners discuss the food system across geography, across demographics, and across politics, yet I rarely hear time mentioned as an element in conversations about creating economic change in our food system. Food system discussions typically involve a series of immediate food and agriculture projects (now) and a longterm idealistic vision for the food system (later), with little mention of strategies to connect the two time periods. It seems as if we are crossing our fingers, closing our eyes, and hoping it all works itself out at some unknown, later date. On the other hand, the study of economics offers a very distinct set of principles on how changes in certain economic factors will affect society and its economy over time. Nevertheless, an integral piece missing from the food system puzzle is the notion of economic change over time, particularly the demand for goods and services in the short term, the labor market in the medium term, and wealth accumulation in the long term (Figure 1).

In macroeconomic theory, economic changes are divided into time periods depending on how many economic factors change before the economy achieves equilibrium. D emand is defined as the quantity of goods and services that consumers are willing and able to buy or barter at different prices. Conversely, supply is the quantity of goods and services that producers are willing and able to sell or barter at different prices. According to Blanchard (2006), the short-run equilibrium is what happens year to year and is defined by changes in

Figure 1. Simplified Timeline of Economic Change

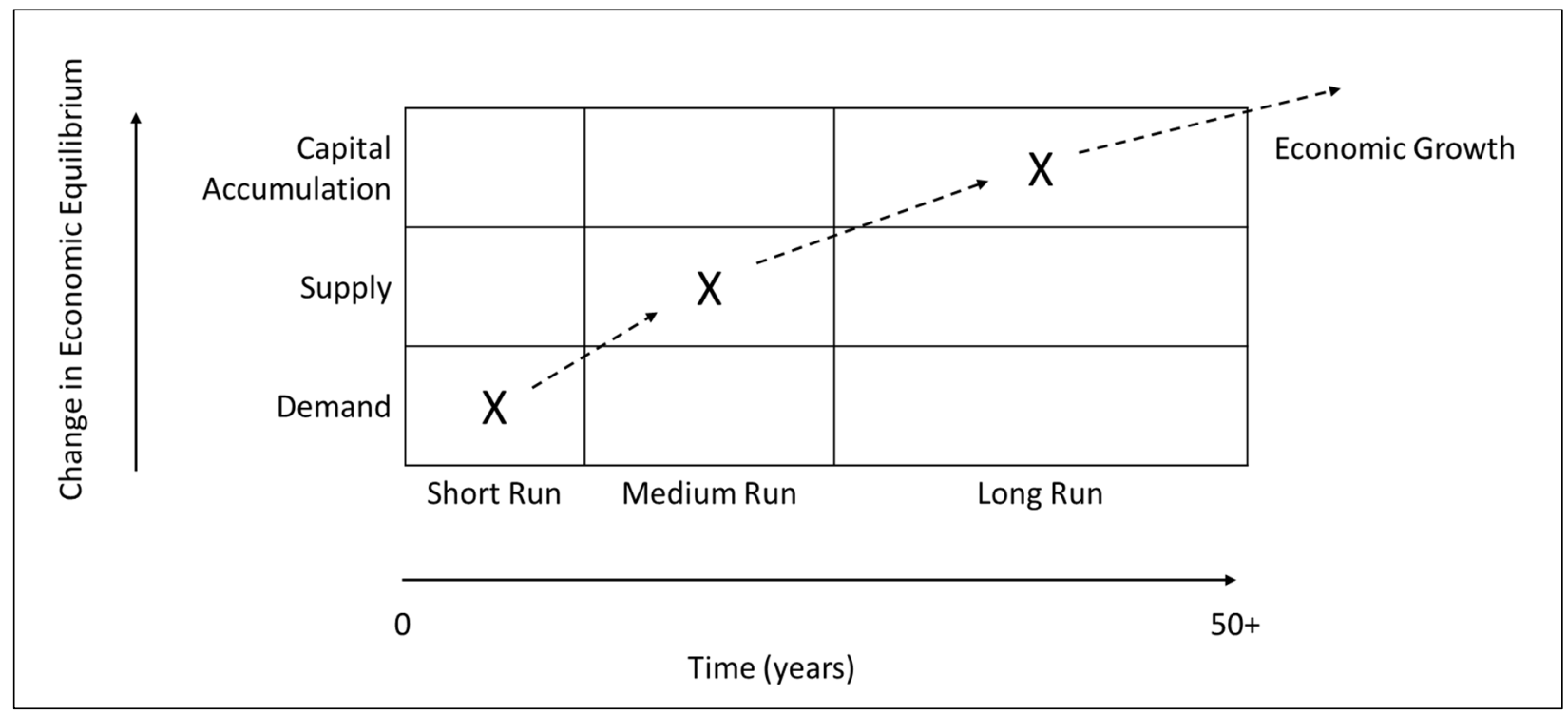


demand. The medium-run equilibrium is what happens over a decade and is defined by changes in production factors, such as labor, technology, and capital (e.g., financial capital, human capital, social capital, etc.). And the long-run equilibrium is what happens over multiple decades and is defined by economic and social factors that sustain growth.

\section{The Short Run: Demand for Goods and Services}

We know that the majority of Americans, across all demographics, do not eat the daily recommended amount of fruit and vegetables. In a society with these preferences, costs to the individual include increased chronic disease and medical costs, while costs to society include increased public health-care costs and reduced economic productivity (Suhrcke, Nugent, Stuckler, \& Rocco, 2006; Wolf \& Colditz, 1998). If food system practitioners want to encourage behavioral changes that lead to economic change in the food system, such as eating more fresh fruits and vegetables, we should start by focusing on increasing demand in the short run. According to economic theory, short-run changes in supply are driven by changes in demand (Blanchard, 2006). Changes in demand can be caused by changes in individual preferences and consumer confidence, among other factors. One might find it manipulative to encourage individuals to increase their consumption of fruit and vegetables to sustain a healthy lifestyle, but as a society, we always make choices about what goods, services, and behaviors have a social benefit. For example, in recent decades, as a society, we have determined that the social costs of smoking cigarettes (e.g., public health-care costs) outweigh the social benefits (e.g., tax revenue from cigarette sales). With this understanding, it is important that we create the demand for a healthy food system as this is a necessary first step before the supply of food, agricultural, and environmental goods and services can adjust.

\section{The Medium Run: The Labor Market}

In the medium run, the economy tends to adjust itself based on supply factors: capital, technology, and the size of the labor force (Blanchard, 2006). Therefore, after demand increases in the short run, capital, technology, and labor adjust to create a new equilibrium in the medium run, where supply changes to meet the new demand. As economists, if we assume that technology and capital are fixed, the size of the labor force then must increase to increase production and supply. As a result, wages also adjust, depending on people's willingness to work in the economy as a whole. According to Biewener (2016), municipal food policy is often concerned with the subject of low-wage workers but shies away from the fact that many of its food and agricultural initiatives are sustained by no-wage workers (i.e., volunteers). If we know the root cause of food insecurity is poverty, it makes no sense as to why so many community food projects with economic justice missions are reliant on nowage labor. If economic theory states that the size of the labor force is a component of the supply of goods and services, we can generally expect that a market that pays no wages will never achieve its fair-wage employment or production goals. Socially, food system practitioners must be mindful of how community food projects signal participation by residents when they do not assign economic value to their labor. Economically, municipal food policy needs to place greater emphasis on community food projects that create increased employment and, potentially, higher wages.

\section{The Long Run: Capital Accumulation}

In the long run, we must look at other factors that perpetuate food insecurity and limited food access. As economic theory suggests, technological improvements, education, savings (capital accumulation), and public policy are all factors contributing to the long-run success of an economy. In a capitalist economic system, the focus is placed on economic growth through accumulating and investing capital, which most often is interpreted to mean financial capital (i.e., money). As municipal food policy practitioners, we must be genuine in our pursuit of inclusive growth and allow all residents to benefit from the accumulation of human, financial, and social capital in the food system. If the United States is currently operating in an economic system where the goal of the game is to amass financial wealth (capitalism), we must support community and economic development 
activities that allow socially disadvantaged residents to accumulate and invest financial capital. At the same time, we can work to redefine capital accumulation to include nuanced forms of capital that are most valuable to a healthy, productive society: human capital, social capital, environmental capital, etc.

\section{Conclusion}

As food policy practitioners, we must be realistic about the society we live in. We all want health, prosperity, and growth within the food system, which will require the right combination of demand, human capital, and individual success. As a society, we will not be able to snap our fingers and undo 13,000 years of agricultural and food system development; genuine structural change will require working across disciplines, across geopolitics, across cultures, and across time. Fortunately, economists have a few thousand years of experience in agriculture, food production, and human behavior - and we are eager to help local residents achieve their food system goals, even if only by demystifying our current economic system.

\section{References}

American Economic Association. (n.d.). W hat is economics? Retrieved March 26, 2019, from https:/ / www.aeaweb.org/ resources/ students/ what-is-economics

Berkes, F., \& Folke, C. (1992). A systems perspective on the interrelations between natural, human-made and cultural capital. E ological E conomics, 5(1), 1-8. http:// hdl.handle.net/ 10535/ 3770

Biewener, C. (2016). Paid work, unpaid work, and economic viability in alternative food initiatives: Reflections from three Boston urban agriculture endeavors. Journal of A griculture, Food Systems, and C ommunity D evelopment, 6(2), 35-53. https:/ / doi.org/ 10.5304/ jafscd.2016.062.019

Blanchard, O. (2006). M acroeconomics (4th Ed.). Upper Saddle River, NJ, USA: Pearson Prentice Hall.

Coleman, J. S. (1988). Social capital in the creation of human capital. The A merican Journal of Sociology, 94, S95-S120. Retrieved from https:/ / www.joumals.uchicago.edu/ toc/ ajs/

Gordon, B. (1975). E onomic analysis before A dam Smith: H esiod to L essius. Basingstoke, England, UK: Palgrave Macmillan.

Hancock, T. (2001). People, partnership, and human progress: Building community capital. H ealth Promotion International, 16(3), 275-280. https:/ / doi.org/ 10.1093/ heapro/ 16.3.275

Lehtonen, M. (2004). The environmental-social interface of sustainable development: Capabilities, social capital, institutions. E ological E conomics, 49(2), 199-214. https:/ / doi.org/ 10.1016/ j.ecolecon.2004.03.019

Suhrcke, M., Nugent, R., Stuckler, D ., \& Rocco, L. (2006). C hronic disease: A n economic perspective. London, UK: The Oxford Health Alliance.

Wolf, A. M., \& Colditz, G . A. (1998). Current estimates of the economic cost of obesity in the United States. 0 besity, 6(2), 97-106. https:/ / doi.org/ 10.1002/ j.1550-8528.1998.tb00322.x 